averaging about 30 per cent; these will be cut by half, to about 15 per cent. On the export side, tariff barriers are also being cut: the EEC tariffs drop from an average of about 15 per cent to 10 per cent; Japan's tariffs drop from an average of 15 per cent to 7.5 per cent; and almost all USA tariffs are being cut by half. This will make British products more competitive with those of the home country but it will also have some side effects. In EFTA, for instance, we can export instruments to Sweden free of charge to compete with those of Sweden, but the tariff cuts mean that instruments from outside EFTA gain competitiveness while ours remain the same. Similar arguments apply to Commonwealth countries, where Commonwealth preference has aided Britain in the past.

Some idea of the effect of the tariff cuts can be gained by considering one particular instrument such as a balance with a sensitivity of five centigrams or better: to import one into Britain a tariff of $33 \frac{1}{3}$ per cent has to be paid, and this will now drop to 17 per cent; the Japanese tariff drops from 15 to 7.5 per cent; the USA tariff from 25 to 12.5 per cent; the EEC tariff from 18 to 9 per cent; and the Swedish tariff for balances from outside EFTA from 10 to 5 per cent. The figures for a thermometer are about the same: Britain's tariff drops from 25 to 12 per cent; Japan's from 15 to 7.5 per cent; the USA tariff on clinical thermometers remains the same at 42.5 per cent, but drops from 42.5 to 21 per cent on all other thermometers; the EEC tariff drops from 17 to 12 per cent; and the Swedish tariff for all thermometers from outside EFTA drops from 10 to 5 per cent.

The report states that not all segments of the industry were equally affected by the "freeze". Optical instruments, which slumped badly in 1965, recorded increased production throughout the year and almost regained their 1964 position. Electrical and electronic instruments made a marked improvement in their export figures, but industrial process measuring and control instruments were badly affected and production for export dropped by 21 per cent. The production of measuring and scientific instruments showed an increase of only 3 per cent.

\section{Patent Law Reform}

The Membership of the Board of Trade Departmental Committee was announced recently by the President of the Board, Mr Douglas Jay. The chairman will be Mr Maurice Banks, who is at present chairman of the Ministry of Technology's Advisory Council on Calibration and Measurement. The other members will be Mr P. J. Stuart Bevan (Deputy Chairman), Mr J. C. Duckworth, Mr G. D. Everington, Mr D. Gladwin, Mr A. W. Mallinson, Mr H. R. Mathys, Mr C. W. Morle, Mr A. Silberston and Professor F. C. Williams. The committee will act with the assistance of the Comptroller-General of the Patent Office.

The formation of the committee comes at a time when revision of patents and patent law is being undertaken in both Europe and America. Indeed, one of the tasks of the committee will be to facilitate the interchange of patent information along the lines agreed by the recent Council of Europe Convention. A standing committee, headed by Mr Mathys, will advise the board on these matters.
What hampers the passage of patent information is, in part, the fact that the establishment of patents involves legal and other problems peculiar to particular countries. In America, the Sherwin Committee (many of whose recommendations are embodied in the Patent Bill now before Congress) suggested the setting up of information centres, in which interlinked computers stored patent information in a standardized system. Such ideas may come to fruition slowly. In the meantime, there may be a case for transferring responsibility for patents from the Board of Trade to the Ministry of Technology. This would be to recognize that patents are as much pieces of scientific information as commercial assets.

\section{All Done by Numbers}

Avy effort to take the guesswork out of engineering is to be commended. To this end, the Institution of Chemical Engineers and the Institution of Mechanical Engineers, with financial backing from the Ministry of Technology, are producing a series of Design Data Memoranda for publication. The first four-approximate data on the viscosity of some common liquids; heat transfer in tubes; thermal conductivity of liquid alcohols; and thermal conductivity of water substances-were launched at a press conference on Tuesday, July 25.

Data sheets were originally pioneered by the Royal Aeronautical Society twenty-six years ago. The Fielden Committee stated in 1963 that they were a way of improving standards of engineering design, and proposed that the work be extended to other fields, and that other professional engineering institutions should participate. It is hoped that the issue of up to date engineering design data will aid engineers in design problem and will save industry from maintaining costly non-specialist data.

\section{Anniversary Conference}

FORTY years ago this year the first announcements of the diffraction of electrons by crystals were made, in letters to Nature by C. Davisson and L. H. Germer, then of Bell Telephone Laboratories, New York, and by G. P. Thomson and A. Reid, of Aberdeen University (Nature, 119, 558 and $890 ; 1927$ ). In commemoration of this anniversary, a conference was held last month at Imperial College, London, under the auspices of the Institute of Physics and the Physical Society (Electron and Microscopy Analysis Group). The conference was opened by Professor C. C. Butler, F.R.S. The two survivors of the four original discoverers, Sir George Thomson, F.R.S., and Professor Germer, each spoke on the history of electron diffraction, Professor Germer reviewing low energy electron diffraction, a field in which he was particularly active until his recent retire. ment.

\section{No Fundamental Length}

\section{from a Correspondent in High Energy Physics}

A RECENT experiment at the Brookhaven National Laboratory (S. J. Lindenbaum et al., Phys. Rev. Letters, 19, 193; 1967) has provided for the first time a critical test of the current concepts of space and time 